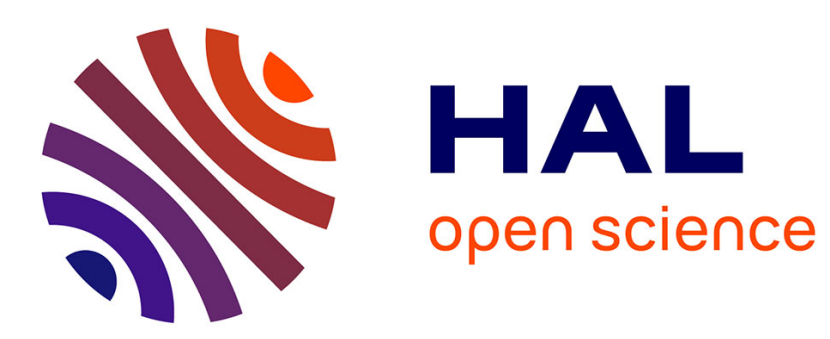

\title{
Transplantation of Zebrafish Cells by Conventional Pneumatic Microinjector
}

Ming Shao, Xiao-Ning Cheng, Yuan-Yuan Li, Ji-Tong Li, De-Li Shi

\section{To cite this version:}

Ming Shao, Xiao-Ning Cheng, Yuan-Yuan Li, Ji-Tong Li, De-Li Shi. Transplantation of Zebrafish Cells by Conventional Pneumatic Microinjector. Zebrafish, In press, 10.1089/zeb.2017.1495 . hal01676124

\section{HAL Id: hal-01676124 https://hal.sorbonne-universite.fr/hal-01676124}

Submitted on 5 Jan 2018

HAL is a multi-disciplinary open access archive for the deposit and dissemination of scientific research documents, whether they are published or not. The documents may come from teaching and research institutions in France or abroad, or from public or private research centers.
L'archive ouverte pluridisciplinaire HAL, est destinée au dépôt et à la diffusion de documents scientifiques de niveau recherche, publiés ou non, émanant des établissements d'enseignement et de recherche français ou étrangers, des laboratoires publics ou privés. 


\section{Transplantation of Zebrafish Cells by Conventional Pneumatic Microinjector}

Ming Shao, Xiao-Ning Cheng, ${ }^{1}$ Yuan-Yuan Liu, Ji-Tong Li, and De-Li Shi ${ }^{1,2}$

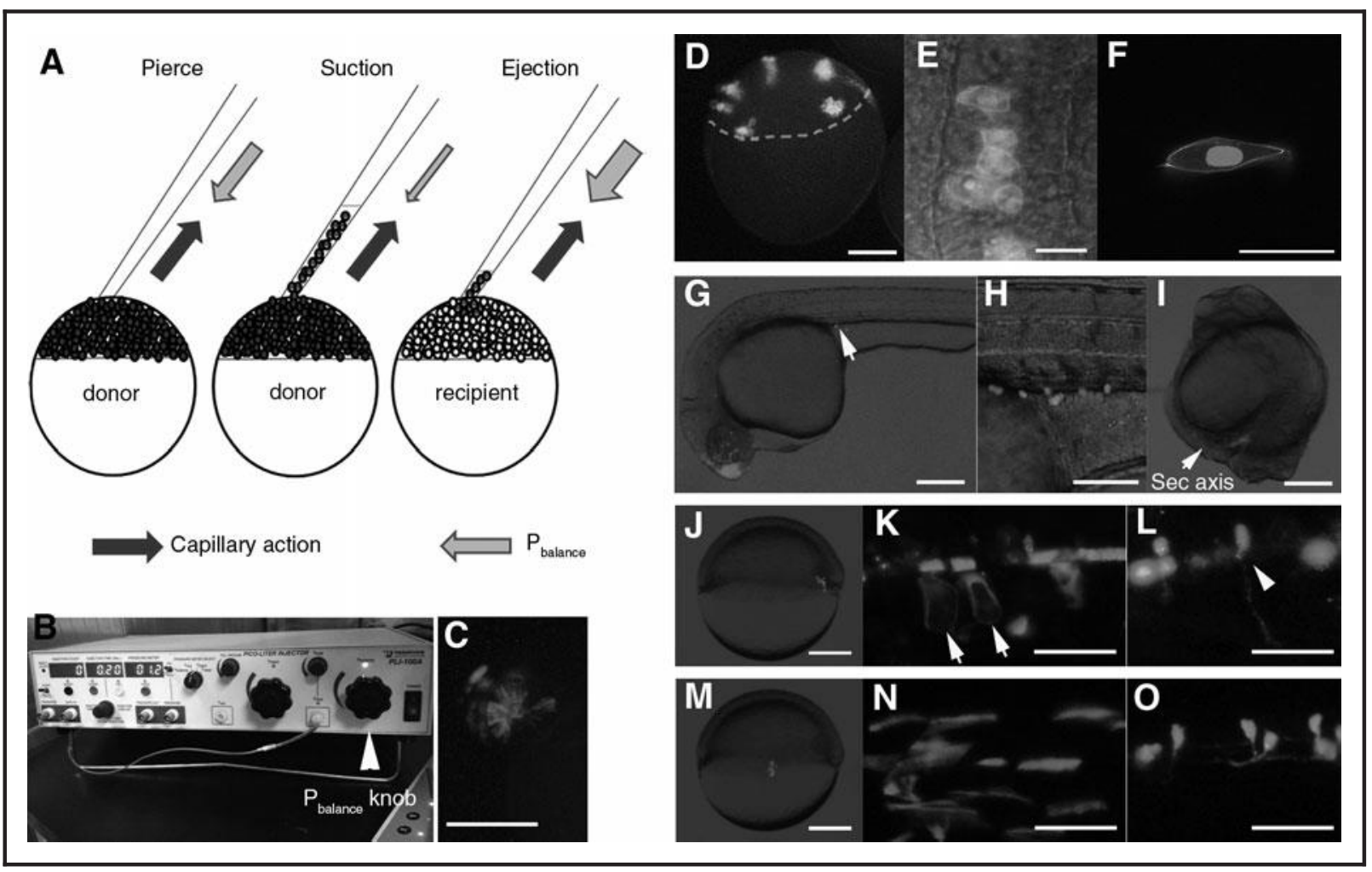

FIG. 1. Transplantation realized by conventional pneumatic microinjector. (A) Schematic of the experimental design. (B) The microinjector used in this study, arrow head designates the knob controlling Pbalance. (C) A representative result of animal pole transplantation at sphere stage. The $24 \mathrm{hpf}$ chimera had RLDx-labeled cells in the retina, lens, and brain. (D) mGFP/H2B-RFP-labeled animal-pole cells were transplanted into six positions around margin of an uninjected recipient at sphere stage. Dashed line designates the boundary between blastodisc and the yolk cell. (E) Labeled cells incorporated into the notochord in a representative bud stage chimera. (F) High magnification of a labeled notochord cell showing a polarized morphology. (G) A 30 hpf chimera embryo with RLDx-labeled PGCs migrating to yolk extension (arrow). (H) High magnification of another chimera showing multiple PGCs in the gonadal mesoderm. (I) The shield cells (red) transplanted to the ventral margin induce an incomplete secondary axis at $24 \mathrm{hpf}$. ( J) Cells from the shield of the labeled donor were introduced to the corresponding region of an unlabeled recipient. $(\mathrm{K}, \mathrm{L})$ This often generates RLDx-labeled notochord cells (arrows) and motor neuron (arrow head). (M) Transplantation of lateral margin cells at shield stage. This usually generates muscle cells (N) and interneurons (O). Scale bars: $200 \mathrm{~lm}$ in C, D, G, I, J, M; $20 \mathrm{~lm}$ in $\mathrm{E}, \mathrm{F}, \mathrm{K}, \mathrm{L}, \mathrm{N}, \mathrm{O} ; 100 \mathrm{~lm}$ in H. PGCs.

${ }^{1}$ School of Life Science, Shandong University, Jinan, China.

${ }^{2}$ IBPS-Developmental Biology Laboratory, UPMC Univ Paris 06, CNRS UMR7622, Sorbonne Universités, Paris, France. 


\section{Abstract}

Generating chimeric zebrafish by transplantation is extremely useful for live imaging in developmental, stem cell, and cancer biology, and to answer the questions of how cells acquire, keep, and/or change their fate. However, as it is technically challenging, the use of transplantation approach remains very limited by the zebrafish community. In this study, we show that this cell grafting operation can be easily achieved by using a conventional pneumatic microinjector normally used for microinjections. Compared with previously published protocols, which need additional transplantation apparatus, this alternative transplantation method works well, but needs a simpler experimental setup, and is more accessible to all investigators.

Keywords: transplantation, zebrafish, pneumatic microinjector

$\mathrm{T}$ ransplantation is a powerful technique with extensive applications in a variety of research purposes. The transparency of zebrafish embryos makes cell engraftment especially useful to live image the morphogenetic movements of cells during gastrulation and organogenesis..$^{1-5}$ It is also an indispensable approach to demonstrate cell autonomous and nonautonoumous function of a specific gene, ${ }^{6}$ to test the effect of different environmental cues on the commitment of cell fate, ${ }^{7}$ and to generate germ line-replaced female zebrafish in the functional analysis of maternal effect genes. ${ }^{8}$ Beside its utility in developmental biology, the technique is also widely applied to answer questions in stem cell and cancer biology. ${ }^{9}$ In transplantation experiment, two controllable actions are required: one is the aspiration of donor cells and the other is their delivery to the recipient embryos. These two actions in previously published protocols are provided by mineral oil-filled systems, ${ }^{6,10,11}$ by a $1-\mathrm{mL}$ syringe, ${ }^{12}$ or by special pneumatic instruments. ${ }^{13}$ The most significant inconveniences of these protocols are the requirement of a special apparatus along with a conventional pneumatic microinjector usually used to label donor embryos at the one-cell stage. These special transplantation devices are either purchased or assembled by DIY, thus increasing the cost and/or the complexity of the experiment. In particular, when oilfilled systems are used, special cautions should be taken to avoid air bubbles and leakage in mounting the needle, as well as potential blockage of the needle by any particle present in mineral oil. All of these points make the traditional technique relatively difficult to master and less accessible, especially for beginners.

To try to solve these issues, we wondered whether the transplantation and microinjection could be realized ' 'all in one' ' by using a conventional pneumatic microinjector, such as the Pico-Liter Injector (PLI-100A) from Harvard Apparatus (United States), which has a large ( $4 \mathrm{~cm}$ in diameter) and smooth $\mathrm{knob}$ to control a positive low pressure $\left(\mathrm{P}_{\text {balance }}\right)$. This pressure, as in many other microinjectors, prevents the fluid uptake through capillary action. Theoretically, the power of aspiration and delivery required by transplantation can be adjusted by tuning the $\mathrm{P}$ balance knob, which controls the equilibration between capillary action and the positive air pressure (Fig. 1A, B). To verify this experimental design, we first performed blastula cell transplantation experiment on an agar-coated Petri dish with a flat laid glass slide. ${ }^{12}$ We found that the cells from the blastodisc of sphere stage embryos can be easily aspirated or released from the transplantation needle just by tuning the $\mathrm{P}_{\text {balance }}$ knob (Supplementary Movie S1; Supplementary Data are available online at www.liebertpub.com/zeb). With this new method, the RLDx-labeled donor cells were found to be present in the brain and retina following their transplantation to the animal pole of unlabeled recipients at the sphere stage (Fig. 1C). We next used this approach to generate chimeric embryos using $\mathrm{mGFP} / \mathrm{H} 2 \mathrm{~B}-\mathrm{RFP}-\mathrm{labeled}$ cells transplanted in the notochord. By introducing labeled cells into multiple separate sites around the margin of unlabeled blastula recipients (Fig. 1D), about $71.4 \%$ of $10 \mathrm{hpf}$ chimeras $(n=28)$ have fluorescent cells in the notochord (Fig. 1E). Their polarized behaviors during mediolateral intercalation could be clearly traced by live imaging (Fig. 1F, Supplementary Movie S2). This method could be also applied for the grafting procedure in the germ line replacement experiment. By transplanting marginal RLDx-positive cells to the animal pole of 
unlabeled recipients, we successfully obtained embryos with large and bright fluorescent PGCs in the gonadal mesoderm (Fig. $1 \mathrm{G}, \mathrm{H}$; 9.3\%, $n=140$ ). The pneumatic injector was also used in more difficult gastrula cell transplantation to accurately target tissues according to the fate map (Fig. $1 \mathrm{~J}-\mathrm{O}$ ), or to induce axial structures by grafting embryonic shield to the ventral margin (Fig. 1I).

Some points for this pneumatic transplantation should be considered. First, this injector provides a controllable linear and continuous complementary pressure output, as well as a large, smooth, and a labor saving $P_{\text {balance }}$ knob. These characters can make the aspiration and delivery actions significantly comfortable and accurate for transplantation, which can be performed either freehand or micromanipulator assisted. Besides PLI-100A, other available injectors, such as MPPI-3 (ASI), IM series (Narishige), SYS-PV820\&830 (WPI), and PM series (MDI, Inc.), should also be compatible with cell transplantation experiment, pending very limited modification. Second, the needle for pneumatic transplantation should have a long tip to make the capillary action readily controllable. Third, the buffer in which transplantation is performed should not contain any viscous supplement that compromises the capillary action, such as egg albumen.

In summary, this novel transplantation method uses the same microinjection instrument for transplantation and is characterized by a simpler experimental setup and easier operation. Comparable performance of this new method has been verified in this article and several other publications, ${ }^{14,15}$ as well as in our teaching experiments. Thus, it has the potential to become a routine cell transplantation technique in zebrafish laboratories.

\section{Acknowledgments}

The authors thank the members of our laboratory for zebrafish care, and the imaging facility H.Y. Yu, X.M. Zhao at the School of Life Science (Shandong University) for live image acquisition. This work was supported by NSFC (31101038, 31271556, 31471360), laboratory construction and management project (SDU).

\section{Authors' Contributions}

M.S. conceived and designed the experiments. M.S., X.N.C., Y.Y.L., and J.T.L. performed the experiments. M.S. and D.L.S. wrote the article.

\section{Disclosure Statement}

No competing financial interests exist.

\section{References}

1. Jessen JR, Topczewski J, Bingham S, Sepich DS, Marlow F, Chandrasekhar A, et al. Zebrafish trilobite identifies new roles for Strabismus in gastrulation and neuronal movements. Nat Cell Biol 2002;4:610 - 615.

2. Miyagi C, Yamashita S, Ohba Y, Yoshizaki H, Matsuda M, Hirano T. STAT3 noncell-autonomously controls planar cell polarity during zebrafish convergence and extension. J Cell Biol 2004;166:975 - 981.

3. Heisenberg CP, Tada M, Rauch GJ, Saúde L, Concha ML, Geisler R, et al. Silberblick/Wnt11 mediates convergent extension movements during zebrafish gastrulation. Nature 2000;405:76 - 81.

4. Kilian B, Mansukoski H, Barbosa FC, Ulrich F, Tada M, Heisenberg CP. The role of $\mathrm{Ppt} / \mathrm{Wnt5}$ in regulating cell shape and movement during zebrafish gastrulation. Mech Dev 2003;120:467 - 476.

5. Jussila M, Ciruna B. Zebrafish models of non-canonical Wnt/planar cell polarity signalling: fishing for valuable insight into vertebrate polarized cell behavior. Wiley Interdiscip Rev Dev Biol 2017;6:e267.

6. Carmany-Rampey A, Moens CB. Modern mosaic analysis in the zebrafish. Methods 2006;39:228 - 238 .

7. Agathon A, Thisse C, Thisse B. The molecular nature of the zebrafish tail organizer. Nature 2003:424:448 - 452.

8. Ciruna B, Weidinger G, Knaut H, Thisse B, Thisse C, Raz E, et al. Production of maternal-zygotic mutant zebrafi by germ-line replacement. Proc Natl Acad Sci U S A 2002;99:14919 - 14924. 
9. Gansner JM, Dang M, Ammerman M, Zon LI. Transplantation in zebrafish. Methods Cell Biol 2017;138:629 - 647.

10. Kemp HA, Carmany-Rampey A, Moens C. Generating chimeric zebrafish embryos by transplantation. J Vis Exp 2009;29:e1394.

11. Zou J, Wei X. Transplantation of GFP-expressing blastomeres for live imaging of retinal and brain development in chimeric zebrafish embryos. J Vis Exp 2010;41: e1924.

12. Dudczig S, Currie PD, Poggi L, Jusuf PR. In vivo imaging of transgenic gene expression in individual retinal progenitors in chimeric zebrafish embryos to study cell nonautonomous influences. J Vis Exp 2017;121:e55490.

13. Deschene ER, Barresi MJ. Tissue targeted embryonic chimeras: zebrafish gastrula cell transplantation. J Vis Exp 2009;31:e1422.

14. Song Y, Wang M, Mao F, Shao M, Zhao B, Song Z, et al. Knockdown of Pnpla6 protein results in motor neuron defects in zebrafish. Dis Model Mech 2013;6:404 413.

15. Shao M, Liu ZZ, Wang CD, Li HY, Carron C, Zhang HW, et al. Down syndrome critical region protein 5 regulates membrane localization of Wnt receptors, Dishevelled stability and convergent extension in vertebrate embryos. Development 2009;136: $2121-2131$.

Address correspondences to:

Ming Shao, PhD

School of Life Science

Shandong University

27 Shanda Nan Road

Jinan 250100

China

E-mail: shaoming@sdu.edu.cn

De-Li Shi, PhD

IBPS-Developmental Biology Laboratory UPMC Univ Paris 06, CNRS UMR7622

Sorbonne Universités

Paris 75005

France

E-mail: de-li.shi@upmc.fr 


\section{Supplementary Data}

\section{Zebrafish and Embryos}

Zebrafish wild-type strains were raised at $28.5^{\circ} \mathrm{C}$. All animal experiments were approved by the Animal Ethics Committee of Shandong University, and carried out according to the regulations and guidelines.

The embryos at the sphere stage or shield stage were dechorionated by incubation in $1 \mathrm{mg} / \mathrm{mL}$ pronase for $15 \mathrm{~min}$ at room temperature. The chorions were removed by gently pipetting with a fire polished glass Pasteur pipette. The embryos were cultured in $1 / 3$ - Ringer' ssupplemented with penicillin streptomycin.

\section{Microinjection and Transplantation}

The coding sequence of Membrane GFP or Histone2bRFP was subcloned into pCS2 vector, and the recombinant plasmids were linearized with Not $\mathrm{I}$. Capped messenger RNAs (mRNAs) were synthesized by the mMessage mMachine SP6 Kit (Thermo Scientific). For cell lineage tracing, 5 ng FLDx or RLDx were injected into one-cell stage embryos in most experiments. For live imaging of notochord cells, 200 pg membrane GFP mRNAs and 100 pg Histone2BRFP mRNAs were coinjected into each embryo.

The transplantation needle was pulled on a PN-30 puller (Narishige). Compared with the parameters for microinjection needle, the heater and the magnet mains were adjusted to high position, and the magnet sub was low to generate a needle with a much longer tip. The beveled opening of the needle with a diameter of about $30-401 \mathrm{~m}$ was clipped by forceps, and the pointed end was pulled manually on a microforge (MF-900; Narishige).

Both the microinjection and transplantation were realized freehand in an agar-coated Petri dish with a flat laid microscope slide. When performing microinjection, one-cell stage embryos, with chorions intact, were aligned along the edge of the slide into either single or multiple rows. The liquid was removed as much as possible to avoid movements during injections. For transplantation, however, the blastula or gastrula embryos were dechorionated in advance, and were aligned along the edge of the microscope slide immersed in culture medium. The edge of the slide provides a fl ible back support when inserting transplantation needle into the blastodisc. A large amount of cells from one donor embryo were usually aspired into the needle and were transferred to several hosts or to multiple sites of one host embryo. When doing blastula transplantation, it is optional to leave the chorions intact for both donors and hosts. The needle should be cleaned before and after transplantation to maintain similar effi iency in every experiment.

\section{Mounting and Imaging}

The embryos were placed on a coverslip or in a six-well plate (WHB-6-20-B) and mounted in 1.5\% low-melting agarose in $1 / 3$ Ringer' $\mathrm{s}$. Tricane $(0.4 \mathrm{mg} / \mathrm{mL})$ was added to the agarose solution when mounting embryos older than $20 \mathrm{hpf}$. The pictures were taken under a stereomicroscope (LEICA M165 FC) or an upright fluorescent microscope (LEICA DM2500). Live imaging was carried out under a High-Content Live-Cell Imaging System (ImageXpress Micro-4, MD).

SUPPLEMENTARY MOVIE S1. 
